\title{
Developing the intellectual and social capital of universities for sustainable development: innovative competence of the teacher and knowledge management
}

\author{
Aigerim Mynbayeva*, Lazat Spankulova \\ Al-Farabi Kazakh National University, al-Farabi av., 70, 050040, Almaty city, Kazakhstan
}

\begin{abstract}
Intellectual and social capital is becoming an important economic resource for the development of an organization and a country. Universities that represent education, science and innovation are increasingly focusing on improving the intellectual and social capital of workers and organizations. The purpose of the article is to identify the features of the increment of the innovative potential of the university for the development of the intellectual and social capital of the organization as an economic resource for the sustainable development of the university in the era of the Internet and the knowledge society. The study found that in order to increase the intellectual and social capital of an organization, it is necessary to create a special innovative environment for interaction, discussions and trainings at the interdepartmental and interfaculty level of staff and students. The development of the intellectual potential of employees can be ensured through the improvement of the innovative competence of teachers and students. This competence is proposed to include information on knowledge management, knowledge flows, diffusion of innovations, etc. Innovation competence will help to give not only a certain economic effect through the creation of new innovative products or educational services based on cooperation of scientists from different directions, but also strengthen the professional pedagogical competence of teachers.
\end{abstract}

\section{Introduction}

The knowledge triangle "education - science - innovation" is defined by the European Union as a key factor in the growth of the European economy [1]. Universities are the organizations in which these three components are connected, i.e. the "triangle of knowledge" is fully reflected. In addition, on the one hand, universities prepare new specialists for the labor market, thereby participating in the improvement of the productive forces in the economy, on the other hand, universities themselves can create or participate in the creation of new innovative products, technologies and services for society, i.e. they are economic agents. Therefore, a new generation of specialists and teachers need to have

* Corresponding author: umo200709@gmail.com 
innovative competence, enriched with the digital specifics of the modern world, a knowledge society, and environmental knowledge. What are the features and new approaches to the development of innovative competence of both university graduates and teachers, researchers, education managers? What influences new opportunities for human realization in the knowledge society and the economy of innovation? What are the new opportunities for improving the human capital of educational organizations?

The purpose of the article is to identify the features of the increment of the innovative potential of the university for the development of the intellectual and social capital of the organization as an economic resource for the sustainable development of the university in the era of the Internet and the knowledge society.

\section{Materials and research methods}

The article analyzes the economic, psychological and educational literature on the development of innovative competence, knowledge economy, innovative economy and sustainable development, strengthening the intellectual and social capital of an individual and an organization. Within the framework of this study, two directions have been identified and summarized, along which the presentation of the content of the article is carried out. First, human resource management at the university can be aimed at the growth of intellectual and social capital for the sustainable development of the organization, including through the development of the innovative competence of teachers and students, their preparation for innovative activities in the knowledge economy. Second, the innovative competence of a specialist can be enriched and supplemented with knowledge of the theory of the flow of knowledge and innovation, knowledge management, which will create a new resource for the continuous improvement of the knowledge and competencies of specialists, the growth of the intellectual capital of the organization. We will begin the presentation of the material with an analysis of the concepts of intellectual and social capital that affects the innovation capital of universities. Further, we will summarize the approaches to transforming the teacher's professional thinking in line with understanding the economic theory of knowledge/innovation flows and knowledge management for the initiation of innovations by teachers, which can affect both the successful preparation of students and the creation of a new innovative product. The peculiarity of the current situation is in new challenges for the development of universities: the massiveization of the digital format of education, and deeper - understanding of new approaches and requirements to the knowledge economy, innovative economy

\section{Literature Review}

The task of transition from commodity economy to knowledge economy is to increase innovative competence of university graduates, teachers, researchers, and education managers [2-3]. New types of capital - social and intellectual capital of universities are on a par with commodities and energy.

University contribution to economic development is expressed in the formation of human capital. Human capital as one of the main factors of economic development, the driving force of economic growth, is clearly shown in the work of T. Schulz [4]. Such an approach was also substantiated in his time by G. Becker [5]. By creating and disseminating knowledge, universities contribute to the development of the country through their connection to the socio-economic environment.

In postmodern theories of economics and management, much attention is paid to the intellectual and social capital of the enterprise. Intellectual and social capital is a 
component of human capital. As you know, human capital accounts for more than $70 \%$ of the national wealth of the developed countries of the world. For the CIS countries it is only $50 \%$ [6]. Therefore, the domestic task of economic development is associated with the improvement of human capital, and hence the intellectual and social capital of society and the country for sustainable development. Another thesis - in the modern world, about $70 \%$ of the growth in gross domestic product falls on the share of new knowledge embodied in innovative technologies of production and management [7]. New knowledge is also born thanks to highly qualified human resources with innovative competence. Thus, the human resource plays a leading role in the economic development of the organization and the country. The task of the university is to train specialists of a new formation with a high potential for creative, innovative activities, knowledge management.

Consider the concepts of intellectual and social capital in scientific sources. Intellectual capital consists of the knowledge, abilities, skills and values of the organization's specialists [8]. Education influences its improvement. According to B. Salikhov, B. Neymatova, the intellectual capital of an enterprise is associated with economic knowledge and is understood as "actualized creative, morally oriented economic knowledge used to create life values - intellectual products" [9]. Also B.Salikhov describes in more detail the structure of intellectual capital: it includes "institutional capital (organizational), social and technological capital", and connects them with the "triad": "production-relationsinstitutions". "The system of production transactions uses technical and technological knowledge; knowledge of social interactions functions within the framework of relational transactions; forms of socio-economic transactions consist of appropriate institutions"[9]. It is clear that intellectual capital is a constituent of organizational capital and influences it; and in this case, technical and technological capital in the form of knowledge of a specific person can be included in intellectual capital. It is on its development that education can influence. For educational organizations A. Bryk, B. Schneider note that "the task of capacity building is to enable individuals to turn intellectual capital into organizational capital for the possibility of its effective use. This requires a focus on social capital - trust, respect, collaboration and networking. An audit of the social capital possessed by an organization will allow determining not only the quality and scale of internal network mechanisms - who talks to whom, how, when and about what? - but also a level of trust that allows people to feel the opportunity to interact with each other and share their knowledge and experience"[10-11].

As E. Suleimenov and others write "social capital is defined as the potential of mutual trust and mutual assistance, which is purposefully formed in the interpersonal space of an organization. This form of capital, like others, is productive, but unlike them, it arises and is realized in the structure of relations between people and among people" [12]. R. Mikiewicz studied the concepts of social capital used in education. Economically, James Coleman's theory of exchange and the network theory is more relevant [13].

Another definition by E. Luneva: "The social capital of an enterprise should be understood as actualized, purposefully used (in this sense, institutionalized) internal and potential clients" [14]. E. Luneva distinguishes between two types of social capital structural (networks, associations, institutions, rules, regulations governing activities) and cognitive (attitudes, norms, behavior, shared values, trust). The structural type of social capital is associated with both the formal organization, the functional interaction of employees and the informal structure, as well as the networked virtual organization of interaction, trust between teachers, administration and teachers, teachers and students, and external relations. The development of the social capital of the organization will contribute to the sustainable development of the enterprise. 


\section{Research results and discussion}

In domestic practice in universities in the direction of educational activities, an ordered formal faculty-department structure is more developed, and more often an administrative management system, with elements of collegial management. The research institutes of the university have a laboratory organization of activities, a matrix management structure. For greater involvement and activation of the potential of the faculty, a more flexible structure of interaction is required, with a greater openness to innovation. The search for new forms of structures has led, for example, to the fact that at Moscow State University there was a structuring around modern scientific-educational schools [15]; in the work of B.Salikhov, instead of departments, the organization of creative centers [16] is proposed, etc. In order to establish trusting interaction, to build up the social capital of an organization, it is necessary as open communication, a special innovative environment of interaction, discussions and trainings for the teaching staff of the interdepartmental, interfaculty level, for example, in the development of methodological, innovative competence, professional, cognitive, psychological, scientific organizational competence, open scientific seminars, as well as expanding the flow of feedback between the administration, teachers and students. According to E. Rezanova, mistrust among the people of one organization leads to an increase in the organization's "operating costs", imposes an "additional duty". Informal horizontal communication becomes more important than formal communication, and electronic interaction helps to work at a distance with less control. It is important in an organizational culture to develop trusting relationships at the level of individuals; integrating values and goodwill at the organizational level, delegation of authority and awareness; study and development of the components of business reputation, leadership at the level of inter organizational relations [17].

Let's move on to the second direction - the enrichment of intellectual capital through development of innovative competence through knowledge about the diffusion of innovation and "knowledge flows", knowledge management. The need to develop innovative or scientific and innovative competence among specialists of the 21 st century in the domestic tradition is considered in at least three directions: (1) for students-economists, in the framework of mastering the disciplines of innovative space management and comfortable economic conditions, it is necessary to transform the thinking of the organization's employees, motivation and readiness to advance. innovation (2) for students of future researchers of academic science - as a continuation of the scientific culture, the creation of innovative products; (3) for students of the pedagogical specialty - as the ability to use innovations in education and innovative teaching methods. Thus, innovations seem to unite or consolidate education and science. The proposed new approach is as follows. To create a special innovative environment for interaction, in addition to organizational organization, the innovations. Knowledge of the diffusion of innovations and "knowledge flows", knowledge management can give not only a certain economic effect through the creation of new innovative products or educational services based on cooperation of scientists from different directions, but also strengthen professional pedagogical competence. As you know, constructive and connective approaches in education change priorities: there has been a transition from the appropriation of ready-made knowledge by students $\rightarrow$ to the ability to create, produce knowledge as a result of independent cognitive activity. It is important to learn and be able to work with implicit knowledge, various information and data, to think critically and creatively.

Knowledge management is a new direction of the knowledge economy, and is associated with education and innovation. As E. Ignatieva notes, "in knowledge management there is a hierarchy of concepts: data, information, knowledge, competencies, competence" [18]. For the subject of professional and / or innovative activity, it is 
necessary to comprehend the chain of knowledge transition: from implicit knowledge $\rightarrow$ to explicit knowledge (formalization) $\rightarrow$ to materialized or product knowledge [16]. The theory of implicit and explicit knowledge was proposed by M. Polani, developed by the Nonaka-Takeuchi model. Implicit knowledge is difficult to formalize, hidden in the minds of people, it is personalized and associated with the individual experience of a person. Explicit knowledge is conventionally codified. The ratio of explicit and implicit knowledge is often presented in the form of a metaphor of an "iceberg" (figure), under the water of which there is implicit knowledge, and over the water - explicit.

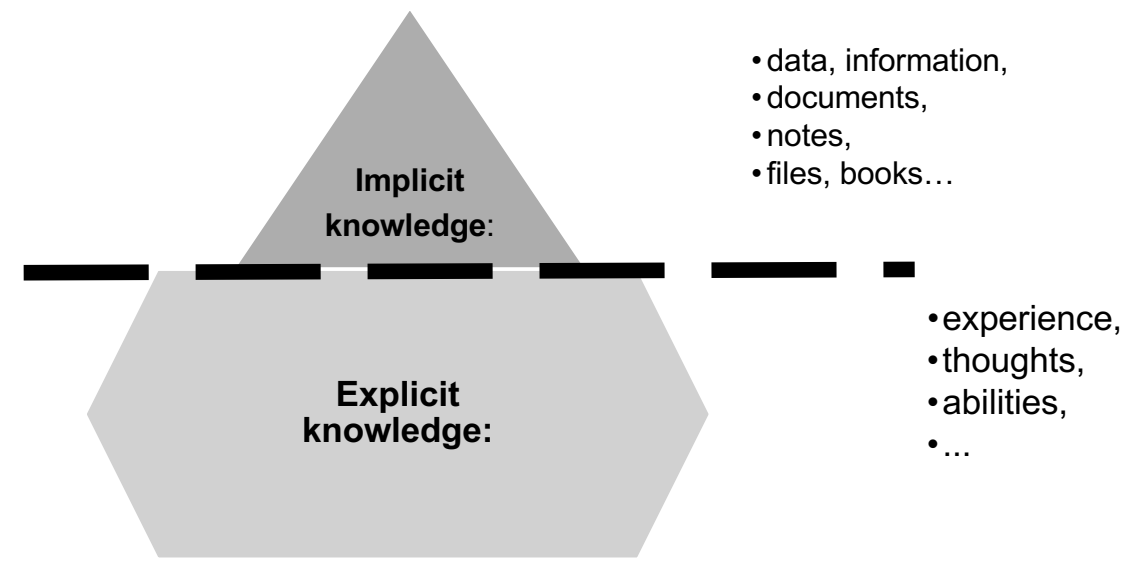

Fig. 1. A metaphor of an "iceberg" of knowledge.

From the point of view of economic theories of innovation, - the transfer of knowledge is not possible without "overflow". L.Spankulova in the monograph "Diffusion of innovations and knowledge flows in the regions of Kazakhstan" [7] describes the genesis of theories of innovation diffusion and knowledge spillovers. "In a broad sense," knowledge flow "refers to situations in which certain legislative actors have the opportunity to obtain knowledge from external sources for free or at minimal cost" [19]. The main channels for the flow of knowledge are education, scientific communications, science-intensive and engineering services, technology transfer, etc. In our opinion, these are external flows of knowledge, from one subject or agent to another. For example, from teacher to student, from one company to another, etc.

On the other hand, if you look from the point of view of the theory of education and science of science, overflows are possible between areas of science as a whole (from one branch of science to another), borrowing ideas that had a great impact on the development of science, the creation of science-intensive products and innovations using associative thinking, insight, gestalt. For example, borrowing ideas / models / theories from physics to psychology, economics, and other sciences. It is known that by analogy with the theory of the physical field, Kurt Lewin in Gestalt psychology created the theory of the "psychological field"; Charles Darwin's theory from biology served as an impetus for the development of functionalism in sociology, etc. Thus, in our opinion, it is possible to recognize the flow of knowledge and ideas between areas of science, and they are associated with human cognitive activity.

Let us consider the phenomenon of diffusion of innovations / knowledge from the point of view of psychological, pedagogical and economic science. On the one hand (psychological and pedagogical science), the diffusion type of thinking is characteristic of the right hemisphere of the brain (according to B. Oakley) for the emergence of creative ideas [20], in other words, we are talking about creative thinking. On the other hand, the 
concept of "diffusionism" is actively used in the economy of innovation. The concept of diffusion is explored by Gabriel Tarde. L.Spankulova examines three stages in the development of innovation diffusionism. "Economic success, intellectual advancing dynamism of science, development and dissemination of innovations by their nature has a diffusional character" [7]. And E. Alekseeva in the monograph "Diffusion of European innovations in Russia" writes: "... The transfer and diffusion of the most important innovations from one country to another is a working paradigm of the theory of modernization ..." [21]. According to L.Spankulova [22], the diffusion of innovation in close connection with innovation is one of the decisive factors in the regional development of Kazakhstan. A. Suvorova highlights and divides the R\&D and the creative industry in the creative capital, when exploring the regions of Russia. She tried to identify the relationship between creative capital and entrepreneurial activity of the population in the regions [23]. It is interesting that in Soviet times V.Baburin, the creative regions (regions implementing the acquired skills) of the former USSR were considered in order of importance: Moscow, Kiev, Minsk, Leningrad, Kharkov, Tomsk, Moscow regions, AlmaAta [24]. Each of these cities became the intellectual leader of scientific and technological progress only after it had gone through a long preparatory period and adopted everything that could be perceived from its neighbors, i.e. there was an overflow of knowledge from other regions. Currently, the Administration of Creative Industries has been created in the Akimat of Almaty [25], on which great hopes are pinned in the development of the city's economy.

Thus, we propose the development of the innovative competence of teachers and students through the study of the theory of knowledge management and knowledge flows in an explicit form. This will contribute to the development of a person's intellectual potential and the growth of the organization's capital.

Improving organizational culture with a focus on teaching innovative competence can contribute to both the development of the professional culture of team members, and affect the strengthening of the intellectual capital of each employee of the university, and strengthen the intellectual capital of the entire organization, the social capital of the university. Innovation competence (as well as environmental, as well as digital competence) is essentially consolidating, in other words, uniting the competence of teachers of different directions, students, university managers. Therefore, it contributes to the sustainable development of the social capital of the organization. In addition, in the Internet age, in cooperation, teachers and students can create new innovative products in the form of various mobile educational applications, MOOCs, electronic textbooks, etc.

\section{Conclusion}

For the development of the intellectual and social capital of the university, it is proposed to create an open innovative environment for the interaction of employees of the interdepartmental and interfaculty levels, as well as the development of the intellectual potential of employees through the improvement of innovative competence. This competence is proposed to include information on knowledge management, knowledge flows, diffusion of innovations, etc. This will affect the productivity of self-realization of university graduates and employees in the knowledge society. Consequently, innovation and competence can influence the further increase in the human capital of an organization and a country, the creation of a new product or service for the sustainable development of the state. Knowledge and innovation management theory continues to expand. In further research, we plan to study the connection between knowledge management and rhizomatic thinking of a modern specialist. 


\section{Acknowledgments}

This research is funded by the Science Committee of the Ministry of Education and Science of the Republic of Kazakhstan (Grant No. AP08856223).

\section{References}

1. Council of the European Union, Conclusion of the Council and of the Representatives of the Governments of the Member States, meeting within the Council on developing the role of education in a fully-functioning knowledge triangle (2009)

2. A.V. Khutorskoy, Key competencies and educational standards, Eidos, 2, 58-64 (2002)

3. I. A. Zimnyaya, Key competences - a new paradigm of the result of education, Higher education today, 5, 34-42 (2003)

4. T. Schulz, Investment in Human Capital, American Economic Revien (1961)

5. G. S. Becker, Human Capital, N.Y.: Columbia University Press (1964)

6. L. Nesterov, National wealth and human capital, Problems of Economics, 2, 103-110 (2003)

7. L. S. Spankulova, Diffusion of innovations and knowledge flows in the regions of Kazakhstan monograph (2020)

8. I. Z. Garafiev, G. I. Garafieva, Evaluation of the company intellectual capital based on the Norton-Kaplan balanced indicator system, IOP Conference Series: Earth and Environmental Science, 650, 1 (2021)

9. B. V. Salikhov, B. A. Neymatova, Functional structure of the intellectual capital of an enterprise as an object of management, Creative Economy, 11, 50-58 (2008)

10. A. Bryk, B. Schneider, Trust in schools: A core resource for improvement, New York: Russell Sage Foundation, 40-45 (2002)

11. N. Yakavets, D. Frost, A. Khoroshash, School leadership and capacity building in Kazakhstan, International Journal of Leadership in Education, 20(3), 345-370 (2017)

12. E. Suleimenov, O. Gabrielyan, I. Pak, S. Panchenko, G. Moon, Innovative scenarios in a post-industrial society (2016)

13. P. Mikiewicz, Social capital and education - an attempt to synthesize conceptualization arising from various theoretical origins, Cogent Education, 8 (1) (2021)

14. E. Luneva, On the question of the essence of social capital as a factor of economic innovation, Transport business in Russia, 2, 126-129 (2011)

15. School system of Moscow University (2021). Access mode: https://nosh.msu.ru/

16. B. Salikhov, I. Salikhova, Scientific and practical imperatives for the development of a modern economy of tacit knowledge, Financial analytics: problems and solutions, 28, 2-11 (2014)

17. E. Rezanova, Social capital of the organization: theoretical and methodological aspects of the study, Nomothetika: Philosophy. Sociology. Law, 7, 2 (57) (2009)

18. E. Ignatieva, About knowledge management and tacit knowledge in education, Higher education in Russia, 12, 36-41 (2006)

19. D. Meisner, Economic effects of the "overflow" of the results of scientific and technical and innovative activities, Foresight, 6(3), 20-31 (2012) 
20. B. Oakley, Learning How to Learn: Powerful Mental Tools to Help You Master Tough Subject (2018). Access mode: https://www.coursera.org/lecture/learning-how-tolearn/using-the-focused-and-diffuse-modes-or-a-little-dali-will-do-you-GVacn

21. E. Alekseeva, Diffusion of European innovations in Russia (XVIII - early XX century), Moscow ROSSPEN (2007)

22. L. Spankulova, Z. Chulanova, S. Ibraimova, Influence of innovation activity, human capital, knowledge flow on the economic growth of regions, Economy: strategy and practice, 4 (14), 53-66 (2019)

23. A. Suvorova, Regional imbalances in the localization of creative capital, E3S Web of Conferences, 301 (2021)

24. V. Baburin, Geography of development of innovative processes within the Russian space (2002)

25. A department of creative industries will be created in Almaty (2021). Access mode: https://kapital.kz/gosudarstvo/93027/v-almaty-sozdadut-upravleniye-kreativnykhindustriy.html 